\title{
THE
}

\section{The Air that we Breathe: Neutral and volatile PFAS in Indoor Air}

Maya E. Morales-McDevitt

University of Rhode Island

Jitka Becanova

University of Rhode Island

Arlene Blum

Thomas A. Bruton

Simon Vojta

University of Rhode Island

Follow this and additional works at: https://digitalcommons.uri.edu/gsofacpubs

The University of Rhode Island Faculty have made this article openly available.

Please let us know how Open Access to this research benefits you.

This is a pre-publication author manuscript of the final, published article.

Terms of Use

This article is made available under the terms and conditions applicable towards Open Access

Policy Articles, as set forth in our Terms of Use.

\section{Citation/Publisher Attribution}

Morales-McDevitt, Maya; Becanova, Jitka; Blum, Arlene; Bruton, Thomas; Vojta, Simon; Woodward, Melissa; Lohmann, Rainer. The Air that we Breathe: Neutral and volatile PFAS in Indoor Air. Environmental Science \& Technology Letters, 2021, accepted. Doi:10.1021/acs.estlett.1c00481.

Available at: https://doi.org/10.1021/acs.estlett.1c00481

This Article is brought to you for free and open access by the Graduate School of Oceanography at DigitalCommons@URI. It has been accepted for inclusion in Graduate School of Oceanography Faculty Publications by an authorized administrator of DigitalCommons@URI. For more information, please contact digitalcommons-group@uri.edu. 


\section{Authors}

Maya E. Morales-McDevitt, Jitka Becanova, Arlene Blum, Thomas A. Bruton, Simon Vojta, Melissa Woodward, and Rainer Lohmann 


\section{The Air that we Breathe: Neutral and volatile PFAS in Indoor Air}

2

3 Maya E. Morales-McDevitt ${ }^{1}$; Jitka Becanova ${ }^{1}$, Arlene Blum ${ }^{2}$, Thomas A. Bruton ${ }^{2}$, Simon

4 Vojta $^{1}$, Melissa Woodward ${ }^{1}$, Rainer Lohmann ${ }^{1, *}$

$5{ }^{1}$ Graduate School of Oceanography, University of Rhode Island, 215 South Ferry Rd,

6 Narragansett, 02882 RI, USA

$7 \quad{ }^{2}$ Green Science Policy Institute, Berkeley, 94709 CA, USA

8

9

* Corresponding author: rlohmann@ uri.edu; Tel (1) 401-874-6612

11 Abstract

Sources of exposure to per- and polyfluorinated alkyl substances (PFAS) include food, water, and given that humans spend typically $90 \%$ of our time indoors, air and dust. Quantifying PFAS prevalent indoors, such as neutral, volatile PFAS, and estimating their exposure risk to humans is thus important. To accurately measure these compounds indoors, polyethylene (PE) sheets were employed and validated as passive detection tools, and analyzed by gas chromatography-mass spectrometry. Air concentrations were compared to dust and carpet concentrations reported elsewhere. Partitioning between PE sheets of different thicknesses suggested that interactions of the PEs with the compounds are occurring by absorption. Volatile PFAS, specifically fluorotelomer alcohols (FTOHs), were ubiquitous in indoor environments. For example, in carpeted Californian kindergarten classrooms, 6:2 FTOH dominated with concentrations ranging from 9-600 $\mathrm{ng} \mathrm{m}^{-3}$, followed by 8:2 FTOH.

23 Concentrations of volatile PFAS from air, carpet and dust were closely related to each other, indicating that carpets and dust are major sources of FTOHs in air. Nonetheless, air posed the largest exposure risk of FTOHs and biotransformed perfluorinated alkyl acids (PFAA) in 
young children. This research highlights inhalation of indoor air as an important exposure pathway and the need for further reduction of precursors to PFAA.

Passive sampling, Polyethylene sheets, PFAS precursors, gas-phase, Carpet, Dust, Risk

Assessment

Polyethylene (PE) sheets are effective passive samplers for PFAA precursors which are ubiquitous in indoor air and dominate indoor exposure.

Introduction

Human exposure to fluorotelomer alcohols (FTOHs), perfluorooctane sulfonamides (FOSAs) and perfluorooctane sulfonamidoethanols (FOSEs) and other precursors to perfluoroalkyl acids (PFAA) comes primarily from consumer and industrial products readily available in people's homes. ${ }^{1-4}$ FTOHs were the dominant polyfluorinated compounds in indoor air ${ }^{5}$ where $\sim 60 \%$ of detected per- and polyfluorinated alkyl substances (PFAS) were associated with the particle phase. ${ }^{2}$ Since most people spend more than $90 \%$ of their time indoors, ${ }^{2}$ indoor air and dust are important uptake pathways for human PFAS exposure ${ }^{6}$ in addition to the widely recognized exposure sources of diet and water. ${ }^{7-9}$ Indeed, correlations between elevated indoor air exposure to precursors and increased PFAS serum concentrations have been reported..$^{10,11}$

The use of passive sampling, which can measure the concentration of freely dissolved or gas-phase trace organic contaminants, has been widely accepted as an effective detection tool. ${ }^{12,13}$ Single-phase polymers, such as polyethylene (PE) sheets, have been able to detect a wide range of non-polar and moderately polar contaminants in the gas phase or dissolved in 
water. ${ }^{14,15}$ In addition, PE sheets are inexpensive, easy to handle, and can be easily transported and deployed. ${ }^{13}$ Recently, neutral PFAS were successfully measured in outdoor air and water using PE sheets. ${ }^{16}$ However, the partitioning of neutral PFAS into or onto the PE sheets indoors is not yet fully understood.

To further assess the role that indoor environments play as an exposure source of airborne PFAS in gas-phase and dust, the main objectives of this research were to (i) derive indoor PE-air partitioning coefficients (K $\mathrm{PE}_{\mathrm{PE} \text {-air }}$; (ii) compare the volatile PFAS composition in different indoor environments using PE sheets as passive samplers; (iii) evaluate the air-dust partitioning of PFAS in carpeted kindergarten classrooms, and (iv) estimate daily intake (EDI)

59 in children 2-6 years of age.

\section{Materials and Methods}

Sampling of neutral PFAS was performed in carpeted kindergarten classrooms, residences, an outdoor gear and apparel store in northern California; university offices, 63 classrooms, laboratories, and a carpet store in southern Rhode Island between 2018 and 2020.

64 A total of $90 \mathrm{PE}$ sheets were deployed in the indoor locations, in addition to eight radiello samplers (Sigma Aldrich) with precleaned XAD-4 as sorbent used for active sampling. Two types of precleaned PE passive samplers differentiated by thickness $(25 \mu \mathrm{m}$ and

$6750 \mu \mathrm{m}$ ) were deployed for 14 days (validation study), 21 days (kinetic study), and 28 days (measurements). Active sampling was performed on days 1, 7 and 14 where the radiello samplers were attached to a QuickTake 30 SKC Pump at a constant flow of $5 \mathrm{~L} \mathrm{~min}^{-1}$ for 240 minutes. All samples were kept in a freezer at $-20^{\circ} \mathrm{C}$ until extraction (for details, see SI). 


\section{Instrumental analysis}

Samples were analyzed for nine neutral PFAS on an Agilent 7890B gas chromatograph coupled to an Agilent 5977A mass selective detector (MSD) device operating in positive chemical ionization mode using selected ion monitoring (for details, see SI).

\section{5}

\section{Data interpretation}

The partitioning constants of neutral PFAS between PE and air (K $\left.\mathrm{KE}_{\mathrm{PE}-\mathrm{air}}\right)$ were derived in the validation study as:

$$
K_{P E-a i r}=\frac{C_{P E}}{C_{\text {air }}}
$$

where $\quad \mathrm{C}_{\mathrm{PE}}$ is the concentration in PE sheets $\left(\mathrm{ng} \mathrm{g}^{-1} \mathrm{PE}\right)$, and $\mathrm{C}_{\text {air }}$ is the gas-phase concentration $\left(\mathrm{ng} \mathrm{m}^{-3}\right)$.

Active sampling was used in the $\mathrm{K}_{\mathrm{PE}-\text { air }}$ validation study only. For all other campaigns, $\mathrm{C}_{\text {air }}$ was calculated using equation (1). Partitioning within the PE sheets was derived as the ratio of the $25 \mu \mathrm{m}$ passive sampler $\left(\mathrm{C}_{25}\right)$ to the $50 \mu \mathrm{m}$ passive sampler $\left(\mathrm{C}_{50}\right)$ amounts at equilibrium (for details, see SI).

\section{Daily intake}

The total estimated daily intake (EDI) of neutral PFAS via air and dust was calculated from PFAS concentrations measured here, and dust concentrations reported elsewhere ${ }^{17}$ based on established methods ${ }^{18,19}$ (for details, see SI).

\section{QA/QC}

Field blanks, matrix spikes, matrix blanks, and field duplicate samples were included with each sample batch. Matrix spikes were prepared by spiking $50 \mu \mathrm{L}$ of an $80 \mathrm{pg} / \mu \mathrm{L}$ native standard solution and $50 \mu \mathrm{L}$ of an $80 \mathrm{pg} / \mu \mathrm{L}$ mass labelled standard solution into a clean (unused and never removed from the laboratory) sampler. Method detection limits (MDL) were calculated as the blank average plus three times the standard deviation; however, when a compound was not detected in the blanks, instrumental limits of detection (ILOD) were used. 
96 Only values above limits of quantitation (LOQ) were reported (for details, see SI, Table S2).

97 Recoveries of the matrix spikes ranged between $81 \%( \pm 35)$ to $111 \%( \pm 19)$ for all compounds

98 (for details, see SI, Table S2).

\section{Results and Discussion}

\section{PE-air Partitioning Constants}

101

Results from the kinetic study showed that 6:2 FTOH and 8:2 FTOH reached equilibrium after 14 days (see SI Figure S1). Log $\mathrm{K}_{\mathrm{PE}-\text { air }}$ values were approximately 4 -5 for the FTOHs, $~ 5$ for 8:2 FTAcr, and increased with molecular weight. Although 10:2 FTAcr, FOSAs and FOSEs were detected by PE sheets, none were detected by active sampling; calculating their equilibrium partitioning constant was not possible (see SI Table S6). There were only minor differences between the $25 \mu \mathrm{m}$ and $50 \mu \mathrm{m} \mathrm{K}_{\mathrm{PE}-\text { air }}$ results, indicating good reproducibility of PE sheets as passive samplers.

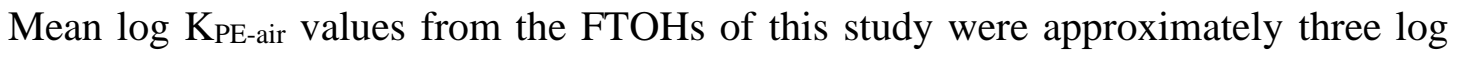

109 units lower than those reported for outdoors (see SI Table S3) ${ }^{16}$ where break-through and

110 environmental factors could have affected the partitioning of the compounds. Missing $\mathrm{K}_{\mathrm{PE}-\mathrm{air}}$

111 values were derived based on a correlation between previously reported ${ }^{16}$ and currently

112 measured PE-air partitioning constants. Further studies are needed to corroborate the

113 partitioning coefficients of the FOSAs and FOSEs.

114

115 Table 1. Indoor log KPE-air values from the validation study for 25 and 50 um PE sheets.

\begin{tabular}{|l|l|l|l|}
\hline Compound & $\begin{array}{l}\text { Molecular weight } \\
\left(\mathrm{g} \mathrm{mol}^{-1}\right)\end{array}$ & $\begin{array}{l}\text { Mean log } \mathrm{K}_{\mathrm{PE}-\text { air } 25} \\
\text { (this study })\end{array}$ & $\begin{array}{l}\text { Mean log } \mathrm{K}_{\mathrm{PE}-\text { air 50 }} \\
\text { (this study })\end{array}$ \\
\hline $6: 2 \mathrm{FTOH}$ & 364.1 & $4.4 \pm 0.1$ & $4.3 \pm 0.0$ \\
\hline $8: 2 \mathrm{FTOH}$ & 464.1 & $4.3 \pm 0.1$ & $4.5 \pm 0.0$ \\
\hline 10:2 FTOH & 564.1 & 5.0 & $5.0 \pm 0.0$ \\
\hline $8: 2 \mathrm{FTAcr}$ & 518.1 & $4.9 \pm 0.4$ & $5.0 \pm 0.2$ \\
\hline
\end{tabular}




\begin{tabular}{|l|l|l|l|}
\hline 10:2 FTAcr & 618.1 & $5.2^{*}$ & $5.3^{*}$ \\
\hline MeFOSA & 527.2 & $5.1^{*}$ & $5.2^{*}$ \\
\hline EtFOSA & 513.1 & ND & ND \\
\hline MeFOSE & 571.2 & $5.2^{*}$ & $5.3^{*}$ \\
\hline EtFOSE & 557.2 & $5.2^{*}$ & $5.2^{*}$ \\
\hline
\end{tabular}

$116 \mathrm{ND}=$ not detected, ${ }^{*} \mathrm{~K}_{\mathrm{PE} \text {-air }}$ from this study was estimated based on a correlation between those measured here and those

117 reported by Dixon-Anderson and Lohmann, (2018) ${ }^{16}$. Estimated KPE-air $=0.44 \mathrm{x}$ K $\mathrm{PE}$-air, measured (Dixon-Anderson and Lohmann,

$1182018)+1.30\left(\right.$ RSQPE $\left.50_{0}=0.67\right)$.

119

\section{PE-air Partitioning ratios}

detection and is thus preferable for future studies.

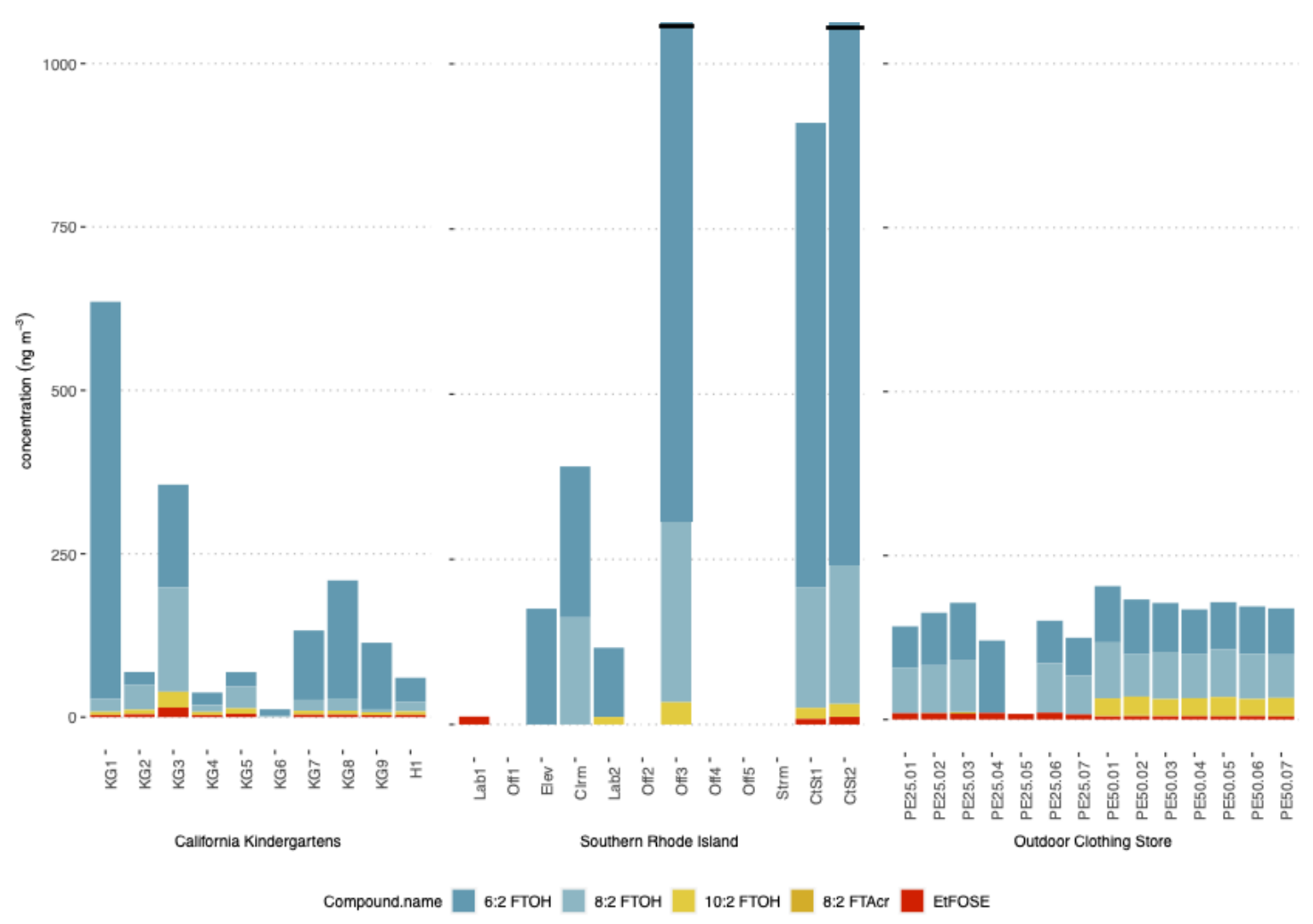

Figure 1. Indoor air concentrations measured at California Kindergarten classrooms 
130 KG7) are indicative of separate/individual samples. Off3 and CtSt2 have concentrations above 1000 $131 \mathrm{ng} \mathrm{m}^{-3}$.

\section{Neutral PFAS Indoor Air Concentrations}

134 Kindergarten classrooms (SI Table S4); (2) offices, classrooms and laboratories at a university,

135 and a nearby carpet store in southern Rhode Island (SI Table S5); and (3) a storage room at an 136 outdoor clothing store in California (SI Table S6), see Figure 1. Neutral PFAS were present at

137 all locations, dominated by FTOHs, in-line with previous results. ${ }^{5,20,21}$ PFAS profiles and 138 concentrations varied between locations, though, likely driven by the different PFAS139 containing products present. These results indicated that PE-sheets can be used to determine 140 differences in PFAS profiles and concentrations in various indoor air settings.

In the California kindergarten classrooms, 6:2 FTOH dominated with concentrations

142 ranging from 10-600 $\mathrm{ng} \mathrm{m}^{-3}$ (accounting for 29-96 \% of sum of nine PFAS), followed by 8:2

143 FTOH (2-160 ng m ${ }^{-3}, 3-54 \%$ of total PFAS) (Figure 1; SI Table S2). In three kindergarten

144 classrooms (KG2, KG3, and KG5), concentrations of 8:2 FTOH exceeded those of 6:2 FTOH.

145 In all kindergarten classrooms, EtFOSE was present at low concentrations, while MeFOSE was 146 below method detection limits (MDLs) (Figure 1; SI Table S2). EtFOSA, 8:2 FTAcr, and 10:2

147 FTAcr were not detected (SI Table 3).

148 When detected, 6:2 FTOH (with detection frequency of 83\%, and ranging from $<$ MDL $\left.149-1900 \mathrm{ng} \mathrm{m}^{-3}\right)$, and 8:2 FTOH (17\%, < MDL-270 $\left.\mathrm{ng} \mathrm{m}^{-3}\right)$ also dominated total PFAS in the 150 university rooms (Figure 1; SI Table S5). FTOHs were detected only in carpeted rooms and in 151 the analytical laboratory (SI Table S5). The detection of 10:2 FTOH was sporadic, with 152 concentrations up to $33 \mathrm{ng} \mathrm{m}^{-3}$ (Figure 1; SI Table S5). MeFOSA, EtFOSE, and MeFOSE were 153 at or < MDL at all sites, while EtFOSA and FTAcr were rarely above MDLs (SI Table S5).

154 Volatile PFAS were present in all replicates from the outdoor clothing store (Figure 1).

155 FTOHs were the most abundant and dominant group; consistent with previous studies on the 
156 composition of PFAS in various indoor environments. ${ }^{5,20,21}$ The most abundant compound was

$1578: 2 \mathrm{FTOH}$, with an average concentration of $\sim 200 \mathrm{ng} \mathrm{m}^{-3}$, followed by $6: 2 \mathrm{FTOH}$ and 10:2

158 FTOH with average concentrations of $70 \mathrm{ng} \mathrm{m}^{-3}$ and $30 \mathrm{ng} \mathrm{m}^{-3}$ respectively (Figure 1). The

159 dominance of 8:2 FTOH is concerning since this and other longer-chain PFAS have been

160 phased out by PFAS producers in the United States, European Union, and Japan ${ }^{22}$. These

161 results show that these compounds are still being used for textiles, and possibly point to textile imports from other countries where PFAS are poorly regulated. ${ }^{23}$

Fraser et al. $(2011)^{11}$ reported concentrations of FTOHs ranging from <MDL to $11 \mathrm{ng}$ $\mathrm{m}^{-3}$ (6:2 FTOH), $0.3-70 \mathrm{ng} \mathrm{m}^{-3}(8: 2 \mathrm{FTOH})$, and $0.14-12 \mathrm{ng} \mathrm{m}^{-3}(10: 2 \mathrm{FTOH})$ in multiple

165 office spaces in Boston, Massachusetts, similar to results report here and in other studies. ${ }^{5,21} \mathrm{~A}$ study in Ottawa, Canada, in 2005 reported concentrations of MeFOSE, EtFOSE and EtFOSA

167 in indoor air of $\sim 7 \mathrm{ng} \mathrm{m}^{-3}, 2 \mathrm{ng} \mathrm{m}^{-3}$ and $0.1 \mathrm{ng} \mathrm{m}^{-3}$, respectively ${ }^{2}$, and even lower in Vancouver, Canada in 2011, at $0.4 \mathrm{ng} \mathrm{m}^{-3}, 0.06 \mathrm{ng} \mathrm{m}^{-3}, 0.03 \mathrm{ng} \mathrm{m}^{-3}$, and $0.02 \mathrm{ng} \mathrm{m}^{-3}$ respectively. ${ }^{21}$ In the present study, although present in many locations, FOSEs rarely exceeded concentrations of

$1700.001 \mathrm{ng} \mathrm{m}^{-3}$. FOSAs were detected even fewer times. The difference in concentrations of the

171 FOSAs and FOSEs in different locations across North America could reflect geographic differences of indoor sources. Additionally, the difference between older and newer data could point to the phase out of PFOS-based chemicals, including FOSAs and FOSEs since 2002, whereas the use of replacement FTOHs in North America has increased since 2000. ${ }^{21,24,25}$

\section{Air-dust-carpet partitioning}

Concentrations of neutral PFAS in dust and carpet of the same kindergarten classrooms were measured by Wu et al. $(2020)^{17}$ (see SI Table S7). Strong correlations (RSQ >0.7, P $\leq 0.05$ ) were observed between different FTOHs in air-dust, and air-carpet (and dust-carpet from Wu 
et al. $(2020)^{17}$, see SI Table S8), except for 6:2 FTOH in air-carpet. On the other hand, FOSEs were not strongly correlated in air, dust or carpet. by partitioning between the gas phase and PFASs sorbed to the organic phases in the dust. ${ }^{26}$

184 Our results corroborated that neutral PFAS were present in air and partitioned to dust. Given 185 that the origin of volatile PFAS in air in the (carpet-free) outdoor clothing storage room was likely to be textiles, it is possible that multiple products in the kindergarten classrooms were in fact the source of these compounds that also partitioned into carpet and dust. Previous work demonstrated that FTOHs, FOSAs, and FOSEs degrade in the atmosphere into more stable PFAA. $^{27,28}$ Significant associations between precursors in air and PFCAs in dust have been

190 reported (e.g., 6:2 FTOH and PFHxA). ${ }^{29}$ Similarly, significant associations were observed between FOSAs/FOSEs in air and PFOS and PFDS in house dust. ${ }^{28}$

In contrast to FTOHs, there were no significant correlations between the FOSAs/FOSEs in air, dust and carpet from this study, suggesting that the sources of FOSAs/FOSEs were different and likely not linked to carpets or textiles. A previous study did not find significant correlations between the FOSEs in kindergarten classrooms either, but did however find strong associations in offices ${ }^{30}$, implying that there were common sources of these sulfonamidoethanols in items associated with office spaces that perhaps were not usually found in kindergarten classrooms. Additionally, as previously mentioned, the production of FOSAs/FOSEs has been largely phased-out of production since $2002^{24}$, and thus their low concentration or absence is expected ${ }^{31}$.

\section{Estimated daily intake of volatile PFAS through air and dust}


exposure estimates (low, medium, high, see SI). Biotransformation constants for each compound were used to calculate their contribution to the $\sum$ PFAA intake (SI Table S8).

$208{ }^{1}$ for intermediate exposure, and $150 \mathrm{ng} \mathrm{kg}^{-1} \mathrm{bw} \mathrm{day}^{-1}$ for high exposure. Compounds that were 209 regularly detected in both air and dust were 6:2 FTOH, 8:2 FTOH, and, to a lesser extent, 10:2

210 FTOH; while MeFOSE and EtFOSE appeared to have significantly larger contributions in dust 211 than air (Figure 2, SI Table S9). Volatile and neutral PFAS measured in air contributed 4.9-62

$212 \%$ to $\sum$ PFAA intake, while ionic PFAS measured in dust contributed 34-95 \% (SI Table S9).

213 These results are similar to other studies that found precursors contributing $41-68 \%$ to $\sum$ PFOS

214 uptake via all investigated exposure pathways, ${ }^{32}$ and precursors responsible for $90 \%$ to the

$215 \sum$ PFOS intake in air (Figure 2). ${ }^{26,33}$ Our results imply that air inhalation was a major exposure

216 pathway for FTOHs, while dust ingestion was dominant for FOSEs in children, similar to prior

217 results. ${ }^{30}$ 

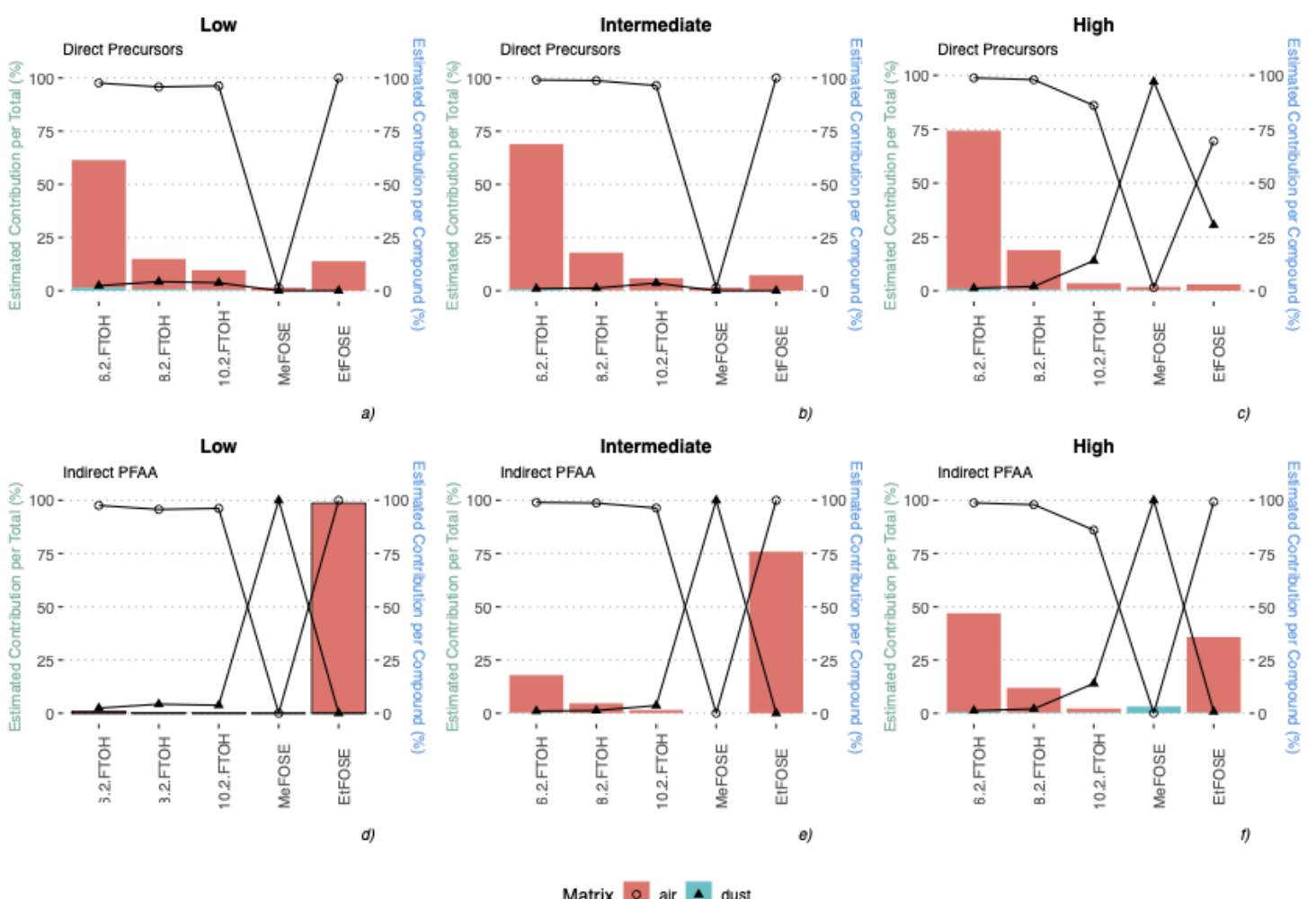

220 Figure 2. Percent of volatile and neutral PFAS (top panel) and indirect or

221 biotransformed PFAA (bottom panel) intake via air inhalation (pink) and dust ingestion (blue) for children at ages 2 through 6 . Bars represent the relative contribution of individual precursors to total PFAS (left axis); bars are differentiated by color for both matrices. Lines represent the percent estimated contribution for each compound in air and dust (right axis). MeFOSE was detected at low concentrations in dust and $<\mathrm{MDL}$ in air.

Given the potential for precursors to be biotransformed into more stable PFAA, estimations of PFAA indirect exposure were also calculated as $1.2 \mathrm{ng} \mathrm{kg}^{-1}$ bw day-1, $75 \mathrm{ng} \mathrm{kg}^{-}$ ${ }^{1} \mathrm{bw} \mathrm{day}^{-1}, 2800 \mathrm{ng} \mathrm{kg}^{-1} \mathrm{bw}$ day $^{-1}$ for the low, intermediate, and high exposure scenario respectively (SI Table S9). The major contributors to indirect PFAA exposure were 6:2 FTOH and 8:2 FTOH in air, and MeFOSE in dust (Figure 2). This study demonstrated that volatile neutral PFAS, such as FTOHs, are major contributors to exposure in air. 
233 Supporting Information

234 The Supporting Information contains additional details on the analysis, data interpretation

235 and EDI calculation, and is available free of charge at https://pubs.acs.org/doi/XXX.

236

237 Acknowledgements

238 The authors acknowledge funding from NIEHS (P42ES027706). The analysis was conducted

239 at a Rhode Island NSF EPSCoR research facility, Molecular Characterization Facility,

240 supported in part by the EPSCoR Cooperative Agreement \# OIA-1655221. We thank Marta

241 Venier (Indiana U) for comments on a previous version of this manuscript.

242

243 Conflict of interest

244 The authors declare no competing financial interests.

245 


\section{References}

248 (1) Prevedouros, K.; Cousins, I. T.; Buck, R.; Korzeniowski, S. H. Critical Review Sources, Fate and Transport of Perfluorocarboxylates. Environ. Sci. Technol. 2006. https://doi.org/10.1021/es0512475.

(2) Shoeib, M.; Harner, T.; Wilford, B. H.; Jones, K. C.; Zhu, J. Perfluorinated Sulfonamides in Indoor and Outdoor Air and Indoor Dust: Occurrence, Partitioning, and Human Exposure. Environ. Sci. Technol. 2005. https://doi.org/10.1021/es048340y.

(3) Langer, V.; Dreyer, A.; Ebinghaus, R. Polyfluorinated Compounds in Residential and Nonresidential Indoor Air. Environ. Sci. Technol. 2010.

(6) Ericson Jogsten, I.; Nadal, M.; Van Bavel, B.; Lindström, G.; Domingo, J. L. Per- and Polyfluorinated Compounds (PFCs) in House Dust and Indoor Air in Catalonia, Spain: Implications for Human Exposure. Environ. Int. 2012, 39, 172-180. https://doi.org/10.1016/j.envint.2011.09.004.

(7) Sunderland, E. M.; Hu, X. C.; Dassuncao, C.; Tokranov, A. K.; Wagner, C. C.; Allen, J. G. A Review of the Pathways of Human Exposure to Poly- and Perfluoroalkyl Substances (PFASs) and Present Understanding of Health Effects. J. Expo. Sci. Environ. Epidemiol. 2019, 29 (2), 131-147. https://doi.org/10.1038/s41370-018-0094- 
EFSA Panel on Contaminants in the Food Chain (EFSA CONTAM Panel); Schrenk,

D.; Bignami, M.; Bodin, L.; Chipman, J. K.; del Mazo, J.; Grasl-Kraupp, B.;

Hogstrand, C.; Hoogenboom, L. (Ron); Leblanc, J.-C.; Nebbia, C.S.; Nielsen, E.;

Ntzani, E.; Petersen, A.; Sand, S.; Vleminckx, C.; Wallace, H.; Barregård, L.;

Ceccatelli, S.; Cravedi, J.P.; Halldorsson, T.I.; et al. Risk to Human Health Related to the Presence of Perfluoroalkyl Substances in Food. EFSA J. 2020, 18 (9), e06223. https://doi.org/https://doi.org/10.2903/j.efsa.2020.6223.

ATSDR. Toxicological Profile for Perfluoroalkyls. (Draft for Public Comment); Atlanta, GA, 2018.

(10) Makey, C. M.; Webster, T. F.; Martin, J. W.; Shoeib, M.; Harner, T.; Dix-cooper, L.;

Webster, G. M. Airborne Precursors Predict Maternal Serum Perfluoroalkyl Acid Concentrations. Env. Sci Technol 2017, 51, 7697-7675.

https://doi.org/10.1021/acs.est.7b00615.

(11) Fraser, A. J.; Webster, T. F.; Watkins, D. J.; Nelson, J. W.; Stapleton, H. M.; Calafat,

A. M.; Kato, K.; Shoeib, M.; Vieira, V. M.; McClean, M. D. Polyfluorinated

Compounds in Serum Linked to Indoor Air in Office Environments. Env. Sci Technol

2011, No. 46, 1209-1215. https://doi.org/10.1021/es2038257.

(12) Lohmann, R. Critical Review of Low-Density Polyethylene's Partitioning and

Diffusion Coefficients for Trace Organic Contaminants and Implications for Its Use

As a Passive Sampler. 2011. https://doi.org/10.1021/es202702y.

(13) Lohmann, R.; Booij, K.; Smedes, F.; Vrana, B. POPs Workshop, Ten Years after the Pollut. Res. 2012, No. 19, 1885-1895. https://doi.org/10.1007/s11356-012-0748-9. 
(14) Booij, K.; Sleiderink, H. M.; Smedes, F. Calibrating the Uptake Kinetics of Semipermeable Membrane Devices Using Exposure Standards. Environ. Toxicol. Chem. 1998, 17 (7), 1236-1245. https://doi.org/10.1897/1551-5028.

(15) Adams, R.; Lohmann, R.; Fernandez, L.; MacFarlane, J.; Gschwend, P. Polyethylene Devices: Passive Samplers for Measuring Dissolved Hydrophobic Organic Compounds in Aquatic Environments. Environ. Sci. Technol 2007. https://doi.org/10.1021/es0621593.

(16) Dixon-Anderson, E.; Lohmann, R. Field-Testing Polyethylene Passive Samplers for the Detection of Neutral Polyfluorinated Alkyl Substances in Air and Water. Environ. Toxicol. Chem. 2018, 37 (12), 3002-2010. https://doi.org/10.1002/etc.4264.

(17) Wu, Y.; Romanak, K.; Bruton, T.; Blum, A.; Venier, M. Per-and Polyfluoroalkyl Substances in Paired Dust and Carpets from Childcare Centers. Chemosphere 2020. https://doi.org/10.1016/j.chemosphere.2020.126771.

(18) USEPA. Exposure Factors Handbook (EFH); Washington, DC, 2008. https://doi.org/EPA/600/R-06/096F.

(19) Gebbink, W.; Berger, U.; Cousins, I. Estimating Human Exposure to PFOS Isomers and PFCA Homologues: The Relative Importance of Direct and Indirect (Precursor) Exposure. Environ. Int. 2015, 74, 160-169. https://doi.org/10.1016/j.envint.2014.10.013.

(20) Liu, W.; Takahashi, S.; Sakuramachi, Y.; Harada, K. H.; Koizumi, A. Polyfluorinated Telomers in Indoor Air of Japanese Houses. 2012. https://doi.org/10.1016/j.chemosphere.2012.09.062.

(21) Shoeib, M.; Harner, T.; Webster, G. M.; Lee, S. C. Indoor Sources of Poly-and Perfluorinated Compounds (PFCS) in Vancouver, Canada: Implications for Human Exposure. Environ. Sci. Technol 2011, 45, 7999-8005. 
https://doi.org/10.1021/es103562v.

(22) Buck, R. C.; Franklin, J.; Berger, U.; Conder, J. M.; Cousins, I. T.; Voogt, P. De; Jensen, A. A.; Kannan, K.; Mabury, S. A.; van Leeuwen, S. P. J. Perfluoroalkyl and Polyfluoroalkyl Substances in the Environment: Terminology, Classification, and Origins. Integr. Environ. Assess. Manag. 2011. https://doi.org/10.1002/ieam.258.

(23) Vestergren, R.; Herzke, D.; Wang, T.; Cousins, I. T. Are Imported Consumer Products an Important Diffuse Source of PFASs to the Norwegian Environment? 2015. https://doi.org/10.1016/j.envpol.2014.12.034.

(24) Barber, J. L.; Berger, U.; Chaemfa, C.; Huber, S.; Jahnke, A.; Temme, C.; Jones, K. C. Analysis of Per- and Polyfluorinated Alkyl Substances in Air Samples from Northwest Europe. J. Environ. Monit. 2007, 9 (6), 530-541. https://doi.org/10.1039/b701417a.

(25) OECD. RESULTS OF THE 2006 SURVEY ON PRODUCTION AND USE OF PFOS, PFAS, PFOA, PFCA, THEIR RELATED SUBSTANCES AND PRODUCTS/MIXTURES CONTAINING THESE SUBSTANCES; 2006. https://doi.org/ENV/JM/MONO(2006)36.

(26) Winkens, K.; Giovanoulis, G.; Koponen, J.; Vestergren, R.; Berger, U.; Karvonen, A.; Pekkanen, J.; Kiviranta, H.; Cousins, I. Perfluoroalkyl Acids and Their Precursors in Floor Dust of Children's Bedrooms - Implications for Indoor Exposure. Environ. Int. 2018, 119 (June), 493-502. https://doi.org/10.1016/j.envint.2018.06.009.

(27) Ellis, D. A.; Martin, J. W.; De Silva, A. O.; Mabury, S. A.; Hurley, M. D.; Sulbaek Andersen, M. P.; Wallington, T. J. Degradation of Fluorotelomer Alcohols: A Likely Atmospheric Source of Perfluorinated Carboxylic Acids. Environ. Sci. Technol. 2004, 38 (12), 3316-3321. https://doi.org/10.1021/es049860w.

(28) Haug, L.; Huber, S.; Schlabach, M.; Becher, G.; Thomsen, C. Investigation on Per-and Polyfluorinated Compounds in Paired Samples of House Dust and Indoor Air from 
Norwegian Homes. Environ. Sci. Technol 2011, 45, 7991-7998. https://doi.org/10.1021/es103456h.

(29) Huber, S.; Haug, L.; Schlabach, M. Per-and Polyfluorinated Compounds in House Dust and Indoor Air from Northern Norway-A Pilot Study. 2011. https://doi.org/10.1016/j.chemosphere.2011.04.075.

(30) Goosey, E.; Harrad, S. Perfluoroalkyl Substances in UK Indoor and Outdoor Air:

(33) Winkens, K.; Koponen, J.; Schuster, J.; Shoeib, M.; Vestergren, R.; Berger, U.;

(32) Vestergren, R.; Cousins, I.; Trudel, D.; Wormuth, M.; Scheringer, M. Estimating the Contribution of Precursor Compounds in Consumer Exposure to PFOS and PFOA. Chemosphere 2008, 73, 1617-1624. https://doi.org/10.1016/j.chemosphere.2008.08.011. 
370

371

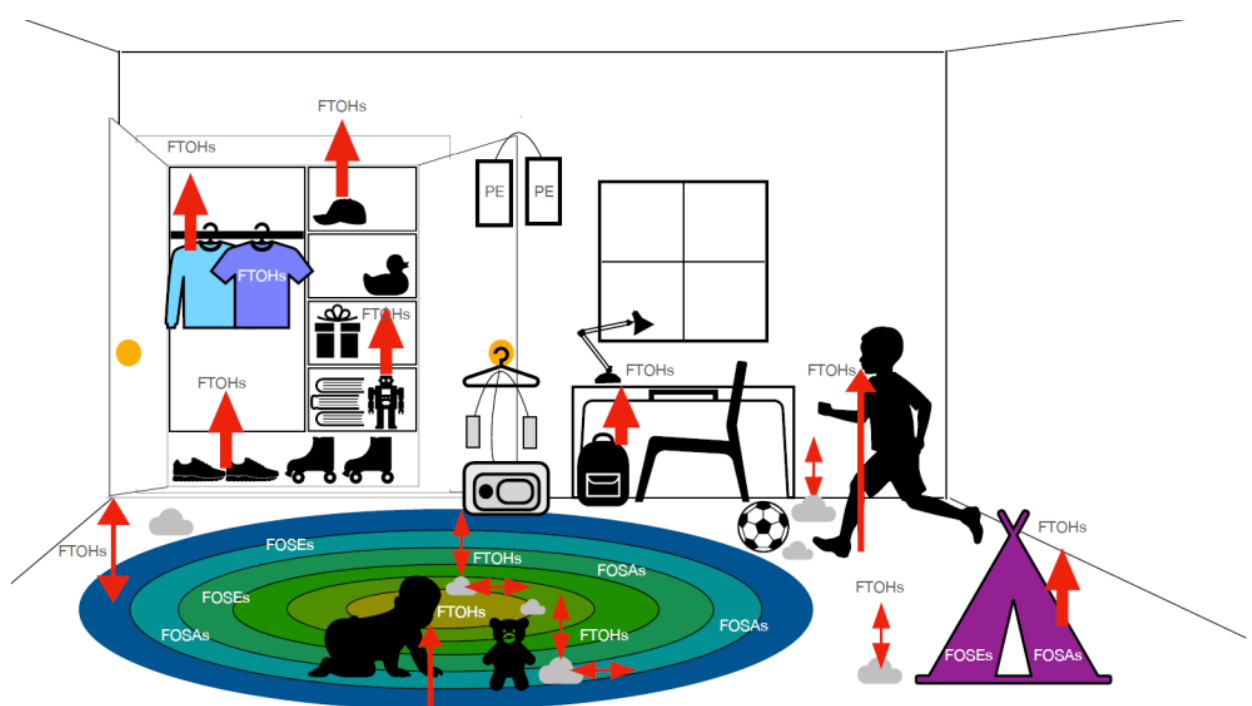

